\title{
Impact of Prior Cerebrovascular Disease and Glucose Status on Incident Cerebrovascular Disease in Japanese
}

\author{
Momoko Oe \\ Niigata University Faculty of Medicine \\ Kazuya Fujihara ( $\nabla$ kafujihara-dm@umin.ac.jp) \\ Niigata Daigaku https://orcid.org/0000-0001-6725-4169 \\ Mayuko Harada Yamada \\ Niigata University Faculty of Medicine \\ Taeko Osawa \\ Niigata University Faculty of Medicine \\ Masaru Kitazawa \\ Niigata University Faculty of Medicine \\ Yasuhiro Matsubayashi \\ Niigata University Faculty of Medicine \\ Takaaki Sato \\ Niigata University Faculty of Medicine \\ Yuta Yaguchi \\ Niigata University Faculty of Medicine \\ Midori Iwanaga \\ Niigata university Faculty of Medicine \\ Hiroyasu Seida \\ JMDC Inc. \\ Takaho Yamada \\ Niigata University Faculty of Medicine \\ Hirohito Sone \\ Niigata University Faculty of Medicine
}

Original investigation

Keywords: diabetes mellitus, borderline glycemia, epidemiology, cerebrovascular disease

Posted Date: July 1st, 2021

DOI: https://doi.org/10.21203/rs.3.rs-665095/v1

License: (c) (1) This work is licensed under a Creative Commons Attribution 4.0 International License. Read Full License 


\section{Abstract}

Background: Although both a history of cerebrovascular disease (CVD) and glucose abnormality are risk factors for CVD, few large studies have examined their association with subsequent CVD in the same cohort. Thus, we compared the impact of prior CVD, glucose status, and their combinations on subsequent CVD using real-world data.

Methods: This is a retrospective cohort study including 363,627 men aged 18-72 years followed for $\geq 3$ years between 2008 and 2016 . Participants were classified as normoglycemia, borderline glycemia, or diabetes defined by fasting plasma glucose, HbA1c, and antidiabetic drug prescription. Prior and subsequent CVD (i.e. ischemic stroke, transient ischemic attack, and non-traumatic intracerebral hemorrhage) were identified according to claims using ICD10 codes, medical procedures, and questionnaires.

Results: The subjects' mean age was $46.1 \pm 9.3$, and median follow up was $5.2(4.2,6.7)$ years. Cox regression analysis showed that prior CVD+ conferred excess risk for CVD regardless of glucose status (normoglycemia: hazard ratio (HR) , 8.77; 95\% Cl, 6.96-11.05; borderline glycemia: HR, 7.40, 95\% Cl, 5.979.17; diabetes: HR, 5.73, 95\% Cl, 4.52-7.25). Compared with the normoglycemia, borderline glycemia did not influence risk of CVD, whereas diabetes affected subsequent CVD in those with CVD- (HR, 1.50, 95\% Cl, 1.34-1.68). In CVD-/diabetes, age, current smoking, systolic blood pressure, HDL cholesterol, and $\mathrm{HbA1c}$ were associated with risk of CVD, but only systolic blood pressure was related to CVD risk in CVD+/diabetes.

Conclusions: Prior CVD had a greater impact on risk of CVD than glucose tolerance and glycemic control. In diabetes with prior CVD, systolic blood pressure was a stronger risk factor than HbA1c. Individualized treatment strategy should consider glucose tolerance status and prior CVD.

\section{Background}

Cerebrovascular disease (CVD) seriously affects not only mortality but also healthy life expectancy, quality of life, and economic well-being. According to a Global Burden of Diseases report, although the age-adjusted stroke mortality rates decreased globally by $36.2 \%$ between 1999 and 2016 , the decline in stroke incidence remained at 8.1\% [1]. Similarly, although CVD deaths are trending lower in Japan [2], stroke has many serious sequelae such as paralysis and dysarthria [3]. In addition, mean cost of post-stroke care per patient month was $\$ 1,515$, which imposes a considerable economic burden [4]. Therefore, to identify patients at high risk for CVD is relevant and urgent with regard to a healthy life expectancy and the economic burden.

A history of CVD greatly increases the risk of subsequent CVD. A meta-analysis showed a recurrence rate of stroke of $3.1 \%$ at 30 days, $11.1 \%$ at 1 year, and $39.2 \%$ at 10 years after the first onset [5]. In Japan, the cumulative recurrence rates were reported to be $35.3 \%$ at 5 years and $51.3 \%$ at 10 years for stroke of all etiologies [6], and $3.81 \%$ at 1 year for ischemic stroke [7].

Diabetes as well as blood pressure is a well-established modifiable risk factor for CVD [8,9]. A meta-analysis reported that diabetes increased the risk of ischemic stroke by approximately 2 -fold and the risk of hemorrhagic stroke by 1.5 -fold in primary prevention [10] and by 1.45 -fold for secondary prevention [11]. On the other hand, there is a lack of consensus on the impact of borderline glycemia on the development of stroke [12-14].

Although diabetes mellitus was considered to be as great a risk for coronary artery disease (CAD) as a history of CAD [15], we showed that borderline glycemia had only a slight impact on CAD regardless of a history of CAD. A history of CAD increased the risk of future CAD 5-8 times whereas diabetes increased the risk of future CAD only about 2 times in Japanese men [16]. In our study, the impact of prior CAD and the glucose status was evaluated in detail with a clear distinction between borderline glycemia and diabetes. However, few large studies have examined the impact of a history of CVD and glucose status on subsequent CVD development [17-19]. Therefore, we investigated the impact of the glucose status and a history of CVD on subsequent CVD in Japanese men using real-world data.

\section{Methods}

The present study retrospectively analyzed data from a nationwide claims-based database that included information on 805,992 people enrolled with a health insurance provider for company employees and their dependents in Japan. Details of the claims data and classifications were described elsewhere [20, 21]. Men aged 18-72 years who had been followed for at least 3 years between 1 April 2008 and 31 July 2016 were included and followed up to 31 August 2019. Excluded were women $(n=297,868)$ because of the lower incidence of CVD, those who were not followed at least 3 years, and those with no health examination data including blood test results $(n=144,497)$. Finally, data were analyzed on 363,627 men.

Participants were classified as having normoglycemia, borderline glycemia, or diabetes mellitus (DM) defined by fasting plasma glucose (FPG), HbA1c, and claims database data as follows: normoglycemia, both $\mathrm{FPG}<5.6 \mathrm{mmol} / \mathrm{L}$ and $\mathrm{HbA} 1 \mathrm{c}<5.7 \%$ (39 mmol/mol) and no antidiabetic drug prescription; borderline glycemia, either FPG 5.6-6.9 mmol/L or HbA1c 5.7-6.4\% (39-46 mmol/mol) or both and no antidiabetic drug prescription; and DM, FPG $\geq 7.0 \mathrm{mmol} / \mathrm{L}$ or $\mathrm{HbA} 1 \mathrm{c} \geq 6.5 \%(47 \mathrm{mmol} / \mathrm{mol})$ or both or with an antidiabetic drug prescription regardless of FPG or HbA1c. Participants who had prior CVD at baseline and subsequent fatal or non-fatal CVD events, such as ischemic stroke, transient ischemic attack, and non-traumatic intracerebral hemorrhage, were determined according to claims using International Classification of Disease 10th revision (ICD-10) codes for CVD and medical procedures and questionnaires [22].

Categorical variables were expressed as numerals and percentages and were compared with $\chi^{2}$ tests. Continuous variables were expressed as mean \pm SD or median and interquartile range. Continuous variables were compared using the unpaired Student's t-test or Mann-Whitney U-test for two group comparisons based on their distributions. Multivariate cox regression hazard model identified variables related to the incidence of CVD. Covariates included factors that have a sufficient number of cases and are not affected by blood collection time, such as age, BMI, systolic blood pressure (SBP), LDL cholesterol (LDL-C), HDL cholesterol (HDL-C) and current smoking, in analyses of the impact of prior CVD and glucose status and their combination. We calculated the hazard

Page $2 / 9$ 
ratio (HR) per 1-SD increment for several variables to directly compare the effect of traditional risk factors. Analyses were performed using SPSS (version 19.0, IBM, Chicago, IL, USA). Statistical significance was considered for $\mathrm{P}<0.05$. The Ethics Committee of Niigata University approved this study.

\section{Results}

Baseline characteristics of our study participants according to glucose status and prior CVD are shown in Table 1. The median follow-up period was 5.2 (4.2, 6.7) years. Among 363,627 participants, $210,434,119,933$, and 33,260 had normoglycemia, borderline glycemia, and DM, respectively. Of those with normoglycemia, borderline glycemia, and DM, 1314, 1240, and 834, respectively, had prior CVD (CVD+). During the study period, 1,025, 961, and 556 CVD events occurred in CVD- and 82, 98, and 85 CVD events occurred in CVD+, respectively, in participants with normoglycemia, borderline glycemia, and DM. The incidence of CVD in CVD- and CVD+ participants were 0.88 and 12.69 in those with normoglycemia, 1.46 and 16.43 in participants with borderline glycemia, and 3.11 and 21.44 in diabetes per 1,000 person-years, respectively.

As shown in Table 1, smoking rate and LDL-C were lower in the CVD+ groups than CVD- group. SBP, HbA1c, FPG, and triglycerides (TG) were lower in CVD- than in CVD+ in those with normoglycemia and borderline glycemia, whereas HbA1c, FPG, and TG were well controlled in CVD+ among DM participants. Percentages of a history of hypertension and dyslipidemia and users of medication for hypertension and dyslipidemia were significantly higher in CVD+. In the DM status, more participants used antidiabetic agents in the CAD+ than in the CAD-group.

In CVD- groups, SBP, diastolic blood pressure (DBP), HbA1c, FPG, TG, and current smoking rate tended to be high, and there was no difference in LDL-C between those with and without new CVD events in the follow-up period in each glucose status. In contrast, among CVD+, the state of control of traditional risk factors at baseline except for SBP was similar among those with or without subsequent CVD events in the borderline glycemia and DM categories (Supplemental Table) [see Additional file].

Table 2 shows the multivariate-adjusted HRs for subsequent CVD events according to glucose status and prior CVD status. For CVD- group, CVD+ groups had approximately 5 - to 8-fold increases in subsequent CVD events regardless of glucose status (rows 1 and 2 from the top). As shown in rows 3 and 4 , the presence of borderline glycemia had no influence on future CVD events independently of prior CVD status. DM affected the incidence of CVD events only in the CVD- group. No additive effect of prior CVD and DM was observed.

Table 3 shows the HRs of each variable on future CVD according to prior CVD and glucose status. In CVD- groups, age, current smoking, SBP, and HDL-C were associated with the risk of incident CVD. On the other hand, in CVD+ groups, SBP was the only factor related to the risk of CVD in borderline glycemia and DM. The impact of a 1 SD increase in SBP was greater in those with normoglycemia than DM, whereas HbA1c was a significant risk factor only in the CVD-/DM group. In the CVD+/normoglycemia group, no traditional risk factor was related to subsequent CVD events. LDL-C was not a risk factor in categories for either glycemia status or prior CVD.

\section{Discussion}

The present study is the first to examine the impact of prior CVD and glucose status on subsequent CVD in a single large population. A history of CVD conferred a 5- to 8-fold increase in subsequent CVD. Diabetes increased the risk of subsequent CVD in participants without a history of CVD whereas borderline glycemia was not related to the risk of subsequent CVD in participants without a history of CVD. On the other hand, neither borderline glycemia nor diabetes increased the risk of subsequent CVD in those with CVD+ (Table 2). These results suggest that the impact of glucose status on CVD is small compared with a history of CVD. This differed from our previous study on CAD in which the combination of CAD+ and diabetes had an additive impact [16]. This may be due to the fact that the effect of blood pressure is much greater on CVD than that of glucose abnormality. In fact, HbA1c was a risk factor in CVD-/DM but not CVD+/DM in an analysis of traditional risk factors (Table 3). SBP was more strongly associated with CVD risk than glycemia in DM with prior CVD. These results indicate that individualized treatment strategies should consider both glucose tolerance status and prior CVD.

In those with CVD+, SBP was associated with the risk of CVD in the borderline glycemia and diabetes groups but not in the normoglycemia group (Table 3). A previous meta-analysis reported that optimal SBP for cardiovascular disease prevention was less than $130 \mathrm{mmHg}[23,24]$. Our results showed that the mean baseline SBP was $123.1 \pm 14.0 \mathrm{mmHg}$ in the normoglycemia group, $127.1 \pm 15.0 \mathrm{mmHg}$ in the borderline glycemia group, and $131.1 \pm 15.8 \mathrm{mmHg}$ in the diabetes group and was lower in the normoglycemia group. When baseline SBP was compared according to the presence or absence of CVD during the follow-up period, occurrence of CVD was significantly higher in those with borderline glycemia and diabetes but not normoglycemia (Supplementary Table). Thus, blood pressure in people with a history of CVD may be well controlled in the absence of abnormal glucose metabolism. The need for stringent antihypertensive treatment was shown by the United Kingdom Prospective Diabetes Study (UKPDS) 38 and the Hypertension Optimal Treatment (HOT) study $[25,26]$. In the present study, although the prescription rate for antihypertensive drugs tended to be highest in DM followed by borderline glycemia and normoglycemia in those with a history of CVD, the mean SBP was higher with worsening of the glucose status. On the other hand, the rate of prescriptions for statins tended to be higher and mean LDL-C values tended to be lower with worsening of the glucose status or with a history of CVD. A history of stroke and diabetes are important risk factors for atherosclerotic disease, and strict control of LDL-C in these patients is recommended in guidelines [27-29]. The significance of comprehensive risk management in diabetes was demonstrated in the Steno-2 study [30, 31] and partly in J-DOIT3 [32]. The results of this study may reflect the situation where LDL-C management is generally successful but that of blood pressure remains an issue especially in patients with abnormal glucose metabolism in Japan.

The strength of our study was combining information on health examinations and from a claims database to assess glucose status based on clinical laboratory values and drug prescriptions and identification of CVD based on ICD-10 codes and procedures. Therefore, we were able to estimate the risk of 
CVD in a real-world setting on a large scale. Also of significance was that our study mainly examined the working generation, which has the greatest impact on economic activity. In addition, only cases with a long-term follow-up of at least three years were evaluated.

However, our study has some limitations. First, we excluded women because of the lower incidence of CVD. Although it was reported that the impact of impaired glucose tolerance on CVD may differ between men and women [33,34], gender differences in incident stroke are greater in East Asia than in Western regions [35]. Thus, a larger cohort is needed to obtain a sufficient number of stroke events in East Asian women for a meaningful analysis. Second, since we do not have data from oral glucose tolerance tests, it is possible that the normoglycemia group included cases with impaired glucose tolerance. Previous studies showed that the impact of glucose abnormality on CVD was different between cases evaluated by fasting blood glucose and those evaluated by oral glucose tolerance test (OGTT) 2-hour values [36, 37]. Although the OGTT is not always routinely performed in health check-ups and clinical settings, it is desirable to construct data that include the results of OGTT. Third, we did not examine each subtype of CVD. Diabetes has been reported to be associated with the risk of ischemic stroke and lacunar infarction, but not with other strokes [38, 39]. However, we used a claims database in the present study to focus on extracting events that have a significant impact on life and functional prognosis rather than on the subtype of CVD. Finally, the impact of changes in glucose abnormality status, other risk factors, and treatment during follow-up could not be examined. It was reported that the transition from borderline glycemia to diabetes increases the risk of cardiovascular disease [40]. To accurately examine the risk of borderline glycemia, it would be necessary to determine whether the participant remained in the status of borderline glycemia or progressed to diabetes during the follow-up.

\section{Conclusion}

A history of CVD greatly increased the risk of subsequent CVD regardless of glucose status. Diabetes increased the risk of CVD in primary prevention, but less in secondary prevention. Individualized treatment strategy is needed in consideration of risk factors, such as glucose tolerance status and prior CVD.

\section{Abbreviations}

$\begin{array}{ll}\text { CAD } & \text { coronary artery disease } \\ \text { CVD } & \text { cerebrovascular disease } \\ \text { DBP } & \text { diastolic blood pressure } \\ \text { DM } & \text { diabetes mellitus } \\ \text { FPG } & \text { fasting plasma glucose } \\ \text { SBP } & \text { systolic blood pressure } \\ \text { TG } & \text { triglycerides }\end{array}$

\section{Declarations}

\section{Ethics approval and consent to participate}

The Ethics Committee of Niigata University approved this study.

\section{Consent for publication}

Not applicable.

\section{Availability of data and materials}

The data that support the findings of this study are available from JMDC Inc. but restrictions apply to the availability of these data, which were used under license for the current study, and so are not publicly available. Data are however available from the authors upon reasonable request and with permission of JMDC Inc..

\section{Competing interests}

M.O. is employees of Kowa Co., Ltd.. No other conflicts of interest relevant to this article exist.

\section{Funding}

This work is supported by JMDC Inc., the Japan Society for Promotion of Science (JSPS), and the Ministry of Health, Labour and Welfare. The sponsor had no role in the design and conduct of the study.

\section{Authors' contributions}

M. O. developed the study design, researched the data, contributed to discussions, wrote the manuscript, and reviewed and edited the manuscript. K. F. planned and supervised this research, researched the data, contributed to discussions, wrote the manuscript, and reviewed and edited the manuscript. M. $\mathrm{H}$. 
Y., T. O., M. K., Y. M., T. Sato, Y. Y., M. I., H. S. and T. Y. researched the data, contributed to discussions, wrote the manuscript and reviewed and edited the manuscript. H. S. developed the study design, contributed to discussions, and reviewed and edited the manuscript.

\section{Acknowledgements}

The authors thank Ms. M. H., Niigata University Faculty of Medicine, for excellent secretarial assistance.

\section{References}

1. GBD 2016 Stroke Collaborators: Johnson CO, Nguyen M, Roth GA, Nichols E, Alam T, Abate D, Abd Allah F, Abdelalim AF, Abraha HN, Abu-Rmeileh NM, et al. Global, regional, and national burden of stroke, 1990-2016: a systematic analysis for the Global Burden of Disease Study 2016. Lancet Neurol. 2019, 18(5): 439-458.

2. Director-General for statistics, Information Policy and Policy Evaluation, Ministry of Health, Labour and Welfare. The Vital Statistics of Japan 2018. Available from https://www.mhlw.go.jp/english/database/db-hw/dl/81-1a2en.pdf.

3. Jørgensen HS, Nakayama H, Raaschou HO, Vive-Larsen J, Støier M, Olsen TS. Outcome and time course of recovery in stroke. Part I: Outcome. The Copenhagen Stroke Study. Arch Phys Med Rehabil. 1995, 76(5): 399-405.

4. Rajsic S, Gothe H, Borba HH, Sroczynski G, Vujicic J, Toell T, Siebert U. Economic burden of stroke: a systematic review on post-stroke care. Eur J Health Econ. 2019, 20(1): 107-134.

5. Mohan KM. Wolfe CD, Rudd AG, Heuschmann PU, Kolominsky-Rabas PL, Grieve AP. Risk and cumulative risk of stroke recurrence: a systematic review and meta-analysis. Stroke. 2011, 42 (5):1489-94.

6. Hata J, Tanizaki Y, Kiyohara Y, Kato I, Kubo M, Tanaka K, Okubo K, Nakamura H, Oishi Y, Ibayashi S, et al. Ten year recurrence after first ever stroke in a Japanese community: the Hisayama study. J Neurol Neurosurg Psychiatry. 2005, 76(3):368-72.

7. Suzuki N, Sato M, Houkin K, Terayama Y, Uchiyama S, Daida H, Shigematsu H, Goto S, Tanaka K, Origasa H, et al. One-year atherothrombotic vascular events rates in outpatients with recent non-cardioembolic ischemic stroke: the EVEREST (Effective Vascular Event REduction after STroke) registry. $J$ Stroke Cerebrovasc Dis. 2012, 21(4): 245-53.

8. Meschia JF, Bushnell C, Boden-Albala B, Braun LT, Bravata DM, Chaturvedi S, Creager MA, Eckel RH, Elkind MS, Fornage M, et al. Guidelines for the primary prevention of stroke: a statement for healthcare professionals from the American Heart Association/American Stroke Association. Stroke. 2014; 45(12):3754-832.

9. Kleindorfer DO, Towfighi A, Chaturvedi S, Cockroft KM, Gutierrez J, Lombardi-Hill D, Kamel H, Kernan WN, Kittner SJ, Leira EC, et al. 2021 Guideline for the Prevention of Stroke in Patients With Stroke and Transient Ischemic Attack: A Guideline From the American Heart Association/American Stroke Association Stroke. 2021; STR0000000000000375.

10. Emerging Risk Factors Collaboration; Sarwar N, Gao P, Seshasai SRK, Gobin R, Kaptoge S, Angelantonio ED, Ingelsson E, Lawlor DA, Selvin E, Stampfer $\mathrm{M}$, et al. Diabetes mellitus, fasting blood glucose concentration, and risk of vascular disease: a collaborative meta-analysis of 102 prospective studies. Lancet. 2010, 375(9733): 2215-22.

11. Shou J, Zhou L, Zhu S, Zhang X. Diabetes is an Independent Risk Factor for Stroke Recurrence in Stroke Patients: A Meta-analysis. J Stroke Cerebrovasc Dis. 2015, 24(9):1961-8.

12. Lee M, Saver JL, Hong KS, Song S, Chang KH, Ovbiagele B. Effect of pre-diabetes on future risk of stroke: meta-analysis. BMJ. 2012, 344 : e3564.

13. Mitsios JP, Ekinci El, Mitsios GP, Churilov L, Thijs V. Relationship between Glycated Hemoglobin and Stroke Risk: A Systematic Review and MetaAnalysis. J Am Heart Assoc. 2018, 7(11): e007858.

14. Cai X, Zhang Y, Li M, Wu JH, Mai L, Li J, Yang Y, Hu Y, Huang Y. Association between prediabetes and risk of all cause mortality and cardiovascular disease: updated meta-analysis. BMJ. 2020, 370: $\mathrm{m} 2297$.

15. Haffner SM, Lehto S, Rönnemaa T, Pyörälä K, Laakso M. Mortality from coronary heart disease in subjects with type 2 diabetes and in nondiabetic subjects with and without prior myocardial infarction. N Engl J Med. 1998, 339(4): 229-34.

16. Kitazawa M, Fujihara K, Osawa T, Yamamoto M, Yamada-Harada M, Kaneko M, Yamanaka N, Seida H, et al. Risk of coronary artery disease according to glucose abnormality status and prior coronary artery disease in Japanese men. Metabolism. 2019, 101: 153991

17. Mazza A, Pessina AC, Pavei A, Scarpa R, Tikhonoff V, Casiglia E. Predictors of stroke mortality in elderly people from the general population. The CArdiovascular STudy in the Elderly. Eur J Epidemiol. 2001, 17(12): 1097-104.

18. Giorda CB, Avogaro A, Maggini M, Lombardo F, Mannucci E, Turco S, Alegiani SS, Raschetti R, Velussi M, Ferrannini E; DAI Study Group. Incidence and risk factors for stroke in type 2 diabetic patients: the DAl study. Stroke. 2007, 38(4): 1154-60.

19. Kranenburg G, van der Graaf Y, van der Leeuw J, Nathoe HM, de Borst GJ, Kappelle LJ, Visseren FL, Westerink J; SMART Study Group. The relation between HbA1c and cardiovascular events in patients with type 2 diabetes with and without vascular disease. Diabetes Care. 2015, 38(10): 1930-6.

20. Yamada-Harada M, Fujihara K, Osawa T, Yamamoto M, Kaneko M, Kitazawa M, Matsubayashi Y, Yamada T, Yamanaka N, Seida H, et al. Relationship Between Number of Multiple Risk Factors and Coronary Artery Disease Risk With and Without Diabetes Mellitus. J Clin Endocrinol Metab. 2019, 104: 5084-90.

21. Fujihara K, Igarashi R, Yamamoto M, Ishizawa M, Matsubayasi Y, Matsunaga S, Kato K, Ito C, Koishi M, Yamanaka N, et al. Impact of glucose tolerance status on the development of coronary artery disease among working-age men. Diabetes Metab. 2017, 43(3):261-264. 
22. Fujihara K, Yamada-Harada M, Matsubayashi Y, Kitazawa M, Yamamoto M, Yaguchi Y, Seida H, Kodama S, Akazawa K, Sone H. Accuracy of Japanese claims data in identifying diabetes-related complications. Pharmacoepidemiol Drug Saf. 2021, 30(5):594-601.

23. Bangalore S, Toklu B, Gianos E, Schwartzbard A, Weintraub H, Ogedegbe G, Messerli FH. Optimal Systolic Blood Pressure Target after SPRINT: Insights from a Network Meta-Analysis of Randomized Trials. Am J Med. 2017, 130(6): 707-719. e8.

24. Kitagawa K, Yamamoto Y, Arima H, Maeda T, Sunami N, Kanzawa T, Eguchi K, Kamiyama K, Minematsu K, Ueda S, et al. Effect of Standard vs Intensive Blood Pressure Control on the Risk of Recurrent Stroke: A Randomized Clinical Trial and Meta-analysis. JAMA Neurol. 2019, 76(11): 1309-1318.

25. UK Prospective Diabetes Study Group. Tight blood pressure control and risk of macrovascular and microvascular complications in type 2 diabetes: UKPDS 38. UK Prospective Diabetes Study Group. BMJ. 1998, 317(7160): 703-13.

26. Hansson L, Zanchetti A, Carruthers SG, Dahlöf B, Elmfeldt D, Julius S, Ménard J, Rahn KH, Wedel H, Westerling S. Effects of intensive blood-pressure lowering and low-dose aspirin in patients with hypertension: principal results of the Hypertension Optimal Treatment (HOT) randomised trial. HOT Study Group. Lancet. 1998, 351(9118): 1755-62.

27. Grundy SM, Stone NJ, Bailey AL, Beam C, Birtcher KK, Blumenthal RS, Braun LT, de Ferranti S, Faiella-Tommasino J, Forman DE, et al. 2018AHA/ACC/AACVPR/AAPA/ABC/ACPM/ADA/AGS/APhA/ASPC/NLA/PCNA Guideline on the Management of Blood Cholesterol: A Report of the American College of Cardiology/American Heart Association Task Force on Clinical Practice Guidelines. Circulation. 2019, 139(25): e1082-e1143.

28. Task Force Members; Mach F, Baigent C, Catapano AL, Koskinas KC, Casula M, Badimon L, Chapman MJ, De Backer GG, Delgado V, Ference BA, et al. ESC Committee for Practice Guidelines (CPG); ESC National Cardiac Societies. 2019 ESC/EAS guidelines for the management of dyslipidaemias: Lipid modification to reduce cardiovascular risk. Atherosclerosis. 2019, 290: 140-205.

29. Kinoshita M, Yokote K,Arai H, lida M, Ishigaki Y, Ishibashi S, Umemoto S, Egusa G, Ohmura H, Okamura T, et al. Japan Atherosclerosis Society (JAS) Guidelines for Prevention of Atherosclerotic Cardiovascular Diseases 2017. J Atheroscler Thromb. 2018, 25: 846-984.

30. Gæde P, Vedel P, Larsen N, Jensen GV, Parving HH, Pedersen O. Multifactorial intervention and cardiovascular disease in patients with type 2 diabetes. N Engl J Med. 2003, 348(5): 383-93.

31. Gæde P, Oellgaard J, Kruuse C, Rossing P, Parving HH, Pedersen O. Beneficial impact of intensified multifactorial intervention on risk of stroke: outcome of 21 years of follow-up in the randomised Steno-2 Study. Diabetologia. 2019, 62(9): 1575-1580.

32. Ueki K, Sasako T, Okazaki Y, Kato M, Okahata S, Katsuyama H, Haraguchi M, Morita A, Ohashi K, Hara K, et al. Effect of an intensified multifactorial intervention on cardiovascular outcomes and mortality in type 2 diabetes (J-DOIT3): an open-label, randomised controlled trial. Lancet Diabetes Endocrinol. 2017, 5(12): 951-964.

33. Wang Y, O'Neil A, Jiao Y, Wang L, Huang J, Lan Y, Zhu Y, Yu C. Sex differences in the association between diabetes and risk of cardiovascular disease, cancer, and all-cause and cause-specific mortality: a systematic review and meta-analysis of 5,162,654 participants. BMC Med. $2019,17: 136$.

34. Parizadeh D, Rahimian N, Akbarpour S, Azizi F, Hadaegh F. Sex-specific clinical outcomes of impaired glucose status: A long follow-up from the Tehran Lipid and Glucose Study. Eur J Prev Cardiol. 2019, 26(10): 1080-1091.

35. GBD 2016 Lifetime Risk of Stroke Collaborators; Feigin VL, Nguyen G, Cercy K, Johnson CO, Alam T, Parmar PG, Abajobir AA, Abate KH, Abd-Allah F, Abejie AN, et al. Global, Regional, and Country-Specific Lifetime Risks of Stroke, 1990 and 2016. N Engl J Med. 2018, 379(25):2429-2437.

36. Oizumi T, Daimon M, Jimbu Y, Wada K, Kameda W, Susa S, Yamaguchi H, Ohnuma H, Tominaga M, Kato T. Impaired glucose tolerance is a risk factor for stroke in a Japanese sample--the Funagata study. Metabolism. 2008, 57(3): 333-8.

37. Thacker EL, Psaty BM, McKnight B, Heckbert SR, Longstreth WT Jr, Mukamal KJ, Meigs JB, de Boer IH, Boyko EJ, Carnethon MR, et al. Fasting and postglucose load measures of insulin resistance and risk of ischemic stroke in older adults. Stroke. 2011, 42(12): 3347-51.

38. O'Donnell MJ, Chin SL, Rangarajan S, Xavier D, Liu L, Zhang H, Rao-Melacini P, Zhang X, Pais P, Agapay S, et al. Global and regional effects of potentially modifiable risk factors associated with acute stroke in 32 countries (INTERSTROKE): a case-control study. Lancet. 2016, 388(10046): 761-75.

39. Toni D, Di Angelantonio E, Di Mascio MT, Vinisko R, Bath PM, PRoFESS Study Group. Types of stroke recurrence in patients with ischemic stroke: a substudy from the PRoFESS trial. Int J Stroke. 2014, 9(7): 873-8.

40. Kabootari M, Hasheminia M, Azizi F, Mirbolouk M, Hadaegh F. Change in glucose intolerance status and risk of incident cardiovascular disease: Tehran Lipid and Glucose Study. Cardiovasc Diabetol. 2020, 19(1):41.

\section{Tables}

Table 1. Baseline characteristics of study participants according to glucose status and prior cerebrovascular diseases 


\begin{tabular}{|c|c|c|c|c|c|c|c|c|c|}
\hline Characteristics & Normoglycemia & & $\begin{array}{l}\mathrm{P}- \\
\text { value }\end{array}$ & Border & & $\begin{array}{l}\mathrm{P} \text { - } \\
\text { value }\end{array}$ & Diabetes & & $\begin{array}{l}\mathrm{P}- \\
\text { value }\end{array}$ \\
\hline & Prior CVD(-) & Prior CVD(+) & & Prior CVD(-) & Prior CVD(+) & & Prior CVD(-) & $\begin{array}{l}\text { Prior } \\
\operatorname{CVD}(+)\end{array}$ & \\
\hline & $n=209120$ & $n=1314$ & & $n=118693$ & $n=1240$ & & $n=32426$ & $n=834$ & \\
\hline Age (v) & $43.6 \pm 9.1$ & $51.3 \pm 8.8$ & $<0.001$ & $48.6 \pm 8.5$ & $55.1 \pm 8.0$ & $<0.001$ & $51.9 \pm 8.1$ & $56.9 \pm 7.4$ & $<0.001$ \\
\hline BMI $\left(\mathrm{kg} / \mathrm{m}^{2}\right)$ & $23.0 \pm 3.0$ & $23.4 \pm 3.0$ & $<0.001$ & $24.2 \pm 3.4$ & $24.9 \pm 3.3$ & $<0.001$ & $26.2 \pm 4.3$ & $26.2 \pm 4.2$ & 0.810 \\
\hline $\mathrm{SBP}(\mathrm{mmHg})$ & $119.8 \pm 13.9$ & $123.1 \pm 14.0$ & $<0.001$ & $124.1 \pm 15.1$ & $127.1 \pm 15.0$ & $<0.001$ & $129.9 \pm 16.4$ & $\begin{array}{l}131.1 \pm \\
15.8\end{array}$ & 0.034 \\
\hline $\mathrm{DBP}(\mathrm{mmHg})$ & $74.8 \pm 10.8$ & $77.8 \pm 10.5$ & $<0.001$ & $78.4 \pm 11.1$ & $80.3 \pm 10.2$ & $<0.001$ & $80.9 \pm 11.1$ & $80.2 \pm 10.6$ & 0.040 \\
\hline $\mathrm{HbA} 1 \mathrm{c}(\mathrm{mmol} / \mathrm{mol})$ & $34.1 \pm 2.5$ & $34.4 \pm 2.5$ & $<0.001$ & $38.4 \pm 3.4$ & $38.9 \pm 3.3$ & $<0.001$ & $54.3 \pm 14.9$ & $52.2 \pm 13.0$ & $<0.001$ \\
\hline FPG (mmol/L) & $4.95 \pm 0.35$ & $5.01 \pm 0.35$ & $<0.001$ & $5.64 \pm 0.50$ & $5.70 \pm 0.50$ & $<0.001$ & $7.9 \pm 2.2$ & $7.6 \pm 2.0$ & 0.005 \\
\hline $\begin{array}{l}\text { LDL cholesterol } \\
\text { (mmol/L) }\end{array}$ & $3.12 \pm 0.78$ & $3.02 \pm 0.77$ & $<0.001$ & $3.32 \pm 0.80$ & $3.11 \pm 0.79$ & $<0.001$ & $3.20 \pm 0.84$ & $2.92 \pm 0.85$ & $<0.001$ \\
\hline $\begin{array}{l}\text { HDL cholesterol } \\
\text { ( } \mathrm{mmol} / \mathrm{L})\end{array}$ & $1.53 \pm 0.38$ & $1.52 \pm 0.37$ & 0.829 & $1.48 \pm 0.38$ & $1.45 \pm 0.37$ & 0.004 & $1.37 \pm 0.36$ & $1.38 \pm 0.34$ & 0.556 \\
\hline $\begin{array}{l}\text { Triglycerides } \\
\text { (mmol/L) }\end{array}$ & $1.04(0.73-1.51)$ & $\begin{array}{l}1.08(0.78- \\
1.55)\end{array}$ & 0.006 & $\begin{array}{l}1.25(0.87- \\
1.83)^{-}\end{array}$ & $\begin{array}{l}1.30(0.93- \\
1.83)\end{array}$ & $<0.001$ & $\begin{array}{l}1.47(1.02- \\
2.19)\end{array}$ & $\begin{array}{l}1.35(0.96- \\
2.01)\end{array}$ & $<0.001$ \\
\hline Current smoking (\%) & $78552(37.6)$ & $264(20.1)$ & $<0.001$ & $\begin{array}{l}44319 \\
(37.3)\end{array}$ & $267(21.5)$ & $<0.001$ & $\begin{array}{l}13227 \\
(40.8)\end{array}$ & $207(24.8)$ & $<0.001$ \\
\hline $\begin{array}{l}\text { History of } \\
\text { hypertension (\%) }\end{array}$ & $30960(14.8)$ & $574(43.7)$ & $<0.001$ & $\begin{array}{l}32190 \\
(27.1)\end{array}$ & 734 (59.2) & $<0.001$ & $\begin{array}{l}16057 \\
(49.5)\end{array}$ & $632(75.8)$ & $<0.001$ \\
\hline $\begin{array}{l}\text { History of } \\
\text { dyslipidemia (\%) }\end{array}$ & 87095 (41.6) & $711(54.1)$ & $<0.001$ & $\begin{array}{l}67540 \\
(56.9)\end{array}$ & $824(66.5)$ & $<0.001$ & $\begin{array}{l}23302 \\
(71.9)\end{array}$ & $671(80.5)$ & $<0.001$ \\
\hline \multicolumn{10}{|l|}{ Medications } \\
\hline$\beta$-blockers (\%) & $1391(0.7)$ & $66(5.0)$ & $<0.001$ & $2068(1.7)$ & $95(7.7)$ & $<0.001$ & $1576(4.9)$ & $127(15.2)$ & $<0.001$ \\
\hline ACEs and ARBs (\%) & 7750 (3.7) & $353(26.9)$ & $<0.001$ & 9709 (8.2) & 449 (36.2) & $<0.001$ & $8054(24.8)$ & $448(53.7)$ & $<0.001$ \\
\hline CCBs (\%) & 7318 (3.5) & $312(23.7)$ & $<0.001$ & $9715(8.2)$ & $421(34.0)$ & $<0.001$ & 6728 (20.7) & 378 (45.3) & $<0.001$ \\
\hline Diuretics (\%) & $1260(0.6)$ & $46(3.5)$ & $<0.001$ & $1774(1.5)$ & $97(7.8)$ & $<0.001$ & $1501(4.6)$ & $92(11.0)$ & $<0.001$ \\
\hline Statins (\%) & $5014(2.4)$ & $232(17.7)$ & $<0.001$ & $7212(6.1)$ & $326(26.3)$ & $<0.001$ & 7050 (21.7) & 381 (45.7) & $<0.001$ \\
\hline $\begin{array}{l}\text { Antiplatelet agents } \\
(\%)\end{array}$ & $879(0.4)$ & $327(24.9)$ & $<0.001$ & $1177(1.0)$ & $405(32.7)$ & $<0.001$ & $1508(4.7)$ & $425(51.0)$ & $<0.001$ \\
\hline OHAs (\%) & & & & & & & $13566(41.8)$ & $491(58.9)$ & $<0.001$ \\
\hline GLP-1 (\%) & & & & & & & $105(0.3)$ & $8(1.0)$ & 0.002 \\
\hline Insulin (\%) & & & & & & & $989(3.1)$ & $44(5.3)$ & $<0.001$ \\
\hline
\end{tabular}

Data are presented as mean \pm SD or median (interquartile range), $\mathrm{n}(\%)$. International Federation of Clinical Chemistry and Laboratory Medicine units.

ACEs, angiotensin-converting-enzyme inhibitors; ARBs, angiotensin-receptor blockers; CCBs calcium-channel blockers; CVD, cerebrovascular disease; DBP, diastolic blood pressure; FPG, fasting plasma glucose; GLP-1, glucagon-like peptide 1 receptor agonists; Border, borderline glycemia; OHAs, oral hypoglycemic agents; SBP, systolic blood pressure.

Hypertension was defined as SBP $>140 \mathrm{mmHg}$, DBP $>90 \mathrm{mmHg}$, or treatment for hypertension.

Dyslipidemia was defined as LDL cholesterol $>3.6 \mathrm{mmol} / \mathrm{L}$, $\mathrm{HDL}$ cholesterol $<1.0 \mathrm{mmol} / \mathrm{L}$, triglycerides $>1.6 \mathrm{mmol} / \mathrm{L}$, or treatment for dyslipidemia.

Table 2. Relationship of prior cerebrovascular disease and glucose status to incident cerebrovascular disease 


\begin{tabular}{|c|c|c|c|c|c|c|}
\hline & \multicolumn{2}{|l|}{ Normoglycemia } & \multicolumn{2}{|l|}{ Borderline glycemia } & \multicolumn{2}{|l|}{ Diabetes } \\
\hline & Hazard ratio $(95 \% \mathrm{Cl})$ & P-value & Hazard ratio $(95 \% \mathrm{Cl})$ & P-value & Hazard ratio $(95 \% \mathrm{Cl})$ & P-value \\
\hline Prior CVD- & 1 [Reference] & & 1 [Reference] & & 1 [Reference] & \\
\hline Prior CVD+ & $8.77(6.96-11.05)$ & $<0.001$ & $7.40(5.97-9.17)$ & $<0.001$ & $5.73(4.52-7.25)$ & $<0.001$ \\
\hline Prior CVD- & 1 [Reference] & & $1.06(0.97-1.16)$ & 0.207 & $1.50(1.34-1.68)$ & $<0.001$ \\
\hline Prior CVD+ & 1 [Reference] & & $1.13(0.83-1.53)$ & 0.433 & $1.32(0.94-1.84)$ & 0.110 \\
\hline Prior CVD- & 1 [Reference] & & $1.08(0.99-1.19)$ & 0.088 & $1.55(1.39-1.74)$ & $<0.001$ \\
\hline Prior CVD+ & 9.03 (7.20-11.34) & $<0.001$ & $8.06(6.52-9.98)$ & $<0.001$ & $8.39(6.67-10.56)$ & $<0.001$ \\
\hline Prior CVD- & $0.65(0.58-0.72)$ & $<0.001$ & $0.70(0.63-0.78)$ & $<0.001$ & 1 [Reference] & \\
\hline Prior CVD+ & $5.83(4.61-7.37)$ & $<0.001$ & $5.20(4.19-6.46)$ & $<0.001$ & $5.41(4.30-6.81)$ & $<0.001$ \\
\hline
\end{tabular}

Each variable for CVD adjusted by age, BMI, systolic blood pressure, LDL cholesterol, HDL cholesterol, and current smoking.

CVD, cerebrovascular disease.

Table 3. Impact of risk factors for cerebrovascular disease according to prior cerebrovascular disease and glucose status 
Prior CVD (-)

Normoglycemia

$\mathrm{HR}(95 \% \mathrm{Cl})$

Prior CVD (+)

\begin{tabular}{|c|c|c|c|c|c|c|c|c|c|c|c|c|}
\hline & Normoglycemia & & Border & & Diabetes & & Normoglycemia & & Border & & Diabetes & \\
\hline & $\mathrm{HR}(95 \% \mathrm{Cl})$ & $\mathbf{P}$ & $\begin{array}{l}\text { HR } \\
(95 \% \\
\text { Cl) }\end{array}$ & $\mathbf{P}$ & $\begin{array}{l}\mathrm{HR}(95 \% \\
\mathrm{Cl})\end{array}$ & $\mathrm{P}$ & $\mathrm{HR}(95 \% \mathrm{Cl})$ & $\mathbf{P}$ & $\begin{array}{l}\text { HR } \\
(95 \% \\
\text { Cl) }\end{array}$ & $\mathrm{P}$ & $\begin{array}{l}\mathrm{HR}(95 \% \\
\mathrm{Cl})\end{array}$ & $\mathbf{P}$ \\
\hline $\begin{array}{l}\text { Age (per/y } \\
\text { increase) }\end{array}$ & $1.08(1.07-1.09)$ & $<0.001$ & $\begin{array}{l}1.08 \\
(1.07- \\
1.09)\end{array}$ & $<0.001$ & $\begin{array}{l}1.06 \\
(1.05- \\
1.08)\end{array}$ & $<0.001$ & $1.02(0.99-1.05)$ & 0.122 & $\begin{array}{l}1.03 \\
(1.00- \\
1.06)\end{array}$ & 0.025 & $\begin{array}{l}1.03 \\
(0.99- \\
1.06)\end{array}$ & 0.125 \\
\hline $\begin{array}{l}\text { Current } \\
\text { smoking } \\
\text { (yes/no) }\end{array}$ & $1.48(1.31-1.68)$ & $<0.001$ & $\begin{array}{l}1.54 \\
(1.35- \\
1.75)\end{array}$ & $<0.001$ & $\begin{array}{l}1.54 \\
(1.29- \\
1.82)\end{array}$ & $<0.001$ & $1.23(0.73-2.08)$ & 0.436 & $\begin{array}{l}0.98 \\
(0.60- \\
1.59)\end{array}$ & 0.927 & $\begin{array}{l}1.32 \\
(0.81- \\
2.16)\end{array}$ & 0.261 \\
\hline \multicolumn{13}{|l|}{ BMI } \\
\hline $\begin{array}{l}\text { Per } 5 \\
\mathrm{~kg} / \mathrm{m}^{2} \\
\text { increase }\end{array}$ & $1.10(0.98-1.23)$ & 0.093 & $\begin{array}{l}1.09 \\
(0.98- \\
1.21)\end{array}$ & 0.109 & $\begin{array}{l}0.95 \\
(0.84- \\
1.06)\end{array}$ & 0.335 & $1.02(0.69-1.52)$ & 0.914 & $\begin{array}{l}0.92 \\
(0.66- \\
1.28)\end{array}$ & 0.604 & $\begin{array}{l}1.03 \\
(0.78- \\
1.37)\end{array}$ & 0.819 \\
\hline $\begin{array}{l}\text { Per } 1 \text { SD } \\
\text { increase }\end{array}$ & $1.07(0.99-1.15)$ & & $\begin{array}{l}1.06 \\
(0.99- \\
1.14)\end{array}$ & & $\begin{array}{l}0.96 \\
(0.89- \\
1.04)\end{array}$ & & $1.02(0.77-1.33)$ & & $\begin{array}{l}0.94 \\
(0.75- \\
1.18)\end{array}$ & & $\begin{array}{l}1.02 \\
(0.85- \\
1.24)\end{array}$ & \\
\hline \multicolumn{13}{|l|}{$\begin{array}{l}\text { Systolic } \\
\text { blood } \\
\text { pressure }\end{array}$} \\
\hline $\begin{array}{l}\text { Per } 10 \\
\text { mmHg } \\
\text { increase }\end{array}$ & $1.36(1.31-1.41)$ & $<0.001$ & $\begin{array}{l}1.32 \\
(1.27- \\
1.37)\end{array}$ & $<0.001$ & $\begin{array}{l}1.23 \\
(1.18- \\
1.29)\end{array}$ & $<0.001$ & $1.00(0.85-1.18)$ & 0.965 & $\begin{array}{l}1.18 \\
(1.04- \\
1.34)\end{array}$ & 0.012 & $\begin{array}{l}1.27 \\
(1.12- \\
1.44)\end{array}$ & $<0.001$ \\
\hline $\begin{array}{l}\text { Per } 1 \text { SD } \\
\text { increase }\end{array}$ & $1.58(1.50-1.68)$ & & $\begin{array}{l}1.51 \\
(1.43- \\
1.59)\end{array}$ & & $\begin{array}{l}1.37 \\
(1.28- \\
1.46)\end{array}$ & & $1.01(0.79-1.28)$ & & $\begin{array}{l}1.27 \\
(1.05- \\
1.54)\end{array}$ & & $\begin{array}{l}1.43 \\
(1.19- \\
1.72)\end{array}$ & \\
\hline \multicolumn{13}{|l|}{$\begin{array}{l}\text { LDL } \\
\text { cholesterol }\end{array}$} \\
\hline $\begin{array}{l}\text { Per } 1 \\
\text { mmol/L } \\
\text { increase }\end{array}$ & $0.98(0.90-1.06)$ & 0.606 & $\begin{array}{l}0.97 \\
(0.90- \\
1.06)\end{array}$ & 0.511 & $\begin{array}{l}0.95 \\
(0.86- \\
1.05)\end{array}$ & 0.333 & $0.78(0.58-1.05)$ & 0.096 & $\begin{array}{l}0.93 \\
(0.72- \\
1.21)\end{array}$ & 0.600 & $\begin{array}{l}0.95 \\
(0.74- \\
1.21)\end{array}$ & 0.664 \\
\hline $\begin{array}{l}\text { Per } 1 \text { SD } \\
\text { increase }\end{array}$ & $0.98(0.92-1.05)$ & & $\begin{array}{l}0.98 \\
(0.92- \\
1.04)\end{array}$ & & $\begin{array}{l}0.96 \\
(0.89- \\
1.04)\end{array}$ & & $0.82(0.65-1.04)$ & & $\begin{array}{l}0.95 \\
(0.77- \\
1.16)\end{array}$ & & $\begin{array}{l}0.96 \\
(0.79- \\
1.17)\end{array}$ & \\
\hline \multicolumn{13}{|l|}{$\begin{array}{l}\text { HDL } \\
\text { cholesterol }\end{array}$} \\
\hline $\begin{array}{l}\text { Per } 1 \\
\text { mmol/L } \\
\text { increase }\end{array}$ & $0.82(0.69-0.98)$ & 0.028 & $\begin{array}{l}0.79 \\
(0.66- \\
0.95)\end{array}$ & 0.013 & $\begin{array}{l}0.68 \\
(0.52- \\
0.88)\end{array}$ & 0.003 & $0.94(0.51-1.74)$ & 0.843 & $\begin{array}{l}0.70 \\
(0.39- \\
1.28)\end{array}$ & 0.245 & $\begin{array}{l}1.48 \\
(0.79- \\
2.76)\end{array}$ & 0.224 \\
\hline $\begin{array}{l}\text { Per I SD } \\
\text { increase }\end{array}$ & $0.93(0.87-0.99)$ & & $\begin{array}{l}0.91 \\
(0.85- \\
0.98)\end{array}$ & & $\begin{array}{l}0.86 \\
(0.78- \\
0.95)\end{array}$ & & $0.98(0.77-1.24)$ & & $\begin{array}{l}0.87 \\
(0.70- \\
1.10)\end{array}$ & & $\begin{array}{l}1.16 \\
(0.91- \\
1.47)\end{array}$ & \\
\hline \multicolumn{13}{|l|}{ HbA1c } \\
\hline $\begin{array}{c}\text { Per } 1 \\
\text { mmol/mol } \\
\text { increase }\end{array}$ & $0.98(0.96-1.01)$ & 0.190 & $\begin{array}{l}1.02 \\
(1.00- \\
1.04)\end{array}$ & 0.090 & $\begin{array}{l}1.01 \\
(1.01- \\
1.02)\end{array}$ & $<0.001$ & $0.96(0.88-1.04)$ & 0.327 & $\begin{array}{l}1.02 \\
(0.96- \\
1.09)\end{array}$ & 0.477 & $\begin{array}{l}1.01 \\
(0.99- \\
1.02)\end{array}$ & 0.359 \\
\hline $\begin{array}{l}\text { Per ISD } \\
\text { increase }\end{array}$ & $0.88(0.73-1.06)$ & & $\begin{array}{l}1.14 \\
(0.98- \\
1.32)\end{array}$ & & $\begin{array}{l}1.08 \\
(1.04- \\
1.13)\end{array}$ & & $0.71(0.36-1.40)$ & & $\begin{array}{l}1.18 \\
(0.74- \\
1.88)\end{array}$ & & $\begin{array}{l}1.06 \\
(0.94- \\
1.19)\end{array}$ & \\
\hline
\end{tabular}

Each variable for CVD adjusted for age, current smoking, BMI, systolic blood pressure, LDL cholesterol, HDL cholesterol, and HbA1c.

HR, hazard ratio; Border, borderline glycemia; P, p-value; SD, standard deviation

CVD, cerebrovascular disease.

\section{Supplementary Files}

This is a list of supplementary files associated with this preprint. Click to download.

- Additionalfile.docx 